\title{
Propensity case-matched analysis of off-pump coronary artery bypass grafting in patients with atheromatous aortic disease
}

Ram Sharony, MD

Eugene A. Grossi, MD

Paul C. Saunders, MD

Aubrey C. Galloway, MD

Robert Applebaum, MD

Greg H. Ribakove, MD

Alfred T. Culliford, MD

Marc Kanchuger, MD

Itzhak Kronzon, MD

Stephen B. Colvin, MD
From the Division of Cardiothoracic Surgery, Department of Surgery, New York University School of Medicine, New York, NY.

Supported in part by The Foundation for Research in Cardiac Surgery and Cardiovascular Biology.

Read at the Eighty-third Annual Meeting of The American Association for Thoracic Surgery, Boston, Mass, May 4-7, 2003.

Received for publication May 4, 2003; revisions requested July 9, 2003; accepted for publication Aug 11, 2003.

Address for reprints: Eugene A. Grossi, MD, New York University Medical Center, 530 First Ave, Suite 9V, New York, NY 10016 (E-mail: grossi@cv.med.nyu.edu).

J Thorac Cardiovasc Surg 2004;127:406-13 $0022-5223 / \$ 30.00$

Copyright $(9) 2004$ by The American Association for Thoracic Surgery

doi:10.1016/j.jtcvs.2003.08.011
Objective: Atheromatous aortic disease is a risk factor for excessive mortality and stroke in patients undergoing coronary artery bypass grafting. Outcomes of offpump coronary artery bypass grafting and coronary artery bypass grafting with cardiopulmonary bypass in patients with severe atheromatous aortic disease were compared by propensity case-match methods.

Methods: Routine intraoperative transesophageal echocardiography identified 985 patients undergoing isolated coronary artery bypass grafting with severe atheromatous disease in the aortic arch or ascending aorta. Off-pump coronary artery bypass grafting was performed in 281 patients $(28.5 \%)$. Propensity matched-pairs analysis was used to match patients undergoing off-pump coronary artery bypass grafting ( $\mathrm{n}$ $=245$ ) with patients undergoing coronary artery bypass grafting with cardiopulmonary bypass.

Results: Univariate analysis revealed decreased hospital mortality $(16 / 245,6.5 \%$ vs $28 / 245,11.4 \% ; P=.058)$ and stroke prevalence $(4 / 245,1.6 \%$ vs $14 / 245,5.7 \%$; $P=.03)$ in off-pump coronary artery bypass grafting compared with coronary artery bypass grafting with cardiopulmonary bypass. Freedom from any postoperative complication was higher in off-pump coronary artery bypass grafting compared with coronary artery bypass grafting with cardiopulmonary bypass $(226 / 245,92.2 \%$ vs $196 / 245,80.0 \% ; P<.001)$. Multivariable analysis of preoperative risk factors showed that increased hospital mortality was associated with coronary artery bypass grafting with cardiopulmonary bypass (odds ratio $=2.7 ; P=.01$ ), fewer grafts $(P=.05)$, acute myocardial infarction (odds ratio $=11.5 ; P<.001$ ), chronic obstructive pulmonary disease (odds ratio $=2.4 ; P=.03$ ), previous cardiac surgery (odds ratio $=10.2, P=.05$ ), and peripheral vascular disease (odds ratio $=2.1$; $P=.05)$. Cardiopulmonary bypass was the only independent risk factor for stroke (odds ratio $=3.6, P=.03$ ). At 36 months' follow-up, comparable survival was observed in the off-pump coronary artery bypass grafting and coronary artery bypass grafting with cardiopulmonary bypass groups (74\% vs $72 \%)$. Multivariable analysis revealed that renal disease $(P<.001)$, advanced age $(P<.001)$, previous myocardial infarction $(P=.03)$, and lower number of grafts $(P=.02)$ were independent risks for late mortality.

Conclusions: Patients with severe atherosclerotic aortic disease who undergo offpump coronary artery bypass grafting have a significantly lower prevalence of 
hospital mortality, perioperative stroke, and overall complications than matched patients who underwent coronary artery bypass grafting with cardiopulmonary bypass. Routine intraoperative transesophageal echocardiography identifies severe atheromatous aortic disease and directs the choice of surgical technique.

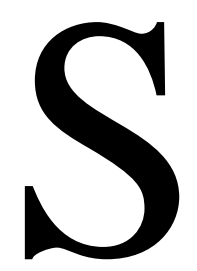

evere atheromatous aortic disease has been identified as an independent risk factor for both mortality and stroke $\mathrm{e}^{1-3}$ in patients undergoing coronary revascularization and can be associated with an operative mortality as high as $14.3 \% .{ }^{4}$ Different surgical techniques have been suggested to minimize the risks of neurologic events in these patients. Such techniques, depending on the location of the disease, have included a "no-touch" technique of the ascending aorta, ${ }^{5}$ internal aortic occlusion, ${ }^{6}$ use of a long aortic cannula, ${ }^{7}$ modification in sites of cannulation and proximal anastomoses, ${ }^{8,9}$ aortic arch endarterectomy, ${ }^{10,11}$ and graft replacement of the ascending aorta. ${ }^{12}$ More recently, intra-aortic filtration has been reported to reduce adverse neurologic events. ${ }^{13}$

Off-pump coronary artery bypass (OPCAB) grafting has gained worldwide popularity ${ }^{14-17}$ and has been associated with less perioperative intra-aortic balloon usage, less postoperative atrial fibrillation, and shorter lengths of stay in the hospital or intensive care unit. ${ }^{15}$ Nonrandomized comparative studies have shown significant reductions in both mortality and major neurologic events with the OPCAB technique. ${ }^{18-22}$ However, previous studies using the propensity case-match methodology have not demonstrated a survival benefit for OPCAB compared with cardiopulmonary bypass $(\mathrm{CPB})^{23,24}$ or have instead focused on global "high-risk" patients. $^{25}$

By the use of transesophageal echocardiography (TEE), we routinely intraoperatively evaluate all patients undergoing coronary revascularization for the presence of atheromatous aortic disease. Such an approach has allowed us to demonstrate that grade and location of aortic atherosclerotic disease are associated with increased perioperative neurologic risk. ${ }^{10,26,27}$ A prior nonmatched comparative study also demonstrated an association between the OPCAB technique and improved outcomes. ${ }^{28}$ The current study uses propensity case matching to explore the relationship between surgical revascularization technique and outcomes in the subset of patients with severe atheromatous aortic disease.

\section{Methods}

Between June 1993 and October 2002, a total of 5976 consecutive patients underwent isolated coronary artery bypass grafting $(\mathrm{CABG})$ at our institution. All patients underwent routine intraoperative TEE evaluation of the aorta. The degree of atherosclerotic disease was graded according to the system developed by Katz and coworkers: ${ }^{26}$ grade $1=$ absence of significant disease, grade $2=$ extensive intimal thickening, grade $3=$ sessile atheroma less than $5 \mathrm{~mm}$ thick, grade $4=$ protruding atheroma more than $5 \mathrm{~mm}$, and grade $5=$ mobile atheroma. Significant atheromatous disease (grade 4 or 5) of the ascending aorta or aortic arch as diagnosed by intraoperative TEE was found in 985 of these patients (16.5\%). If ascending aortic disease was demonstrated on TEE, epiaortic scanning was routinely performed. ${ }^{27,29}$ In the presence of severe ascending aortic atherosclerosis, echocardiography and manual palpation (typically with inflow occlusion) were performed to evaluate potential sites for arterial cannulation and crossclamp application; in these patients, proximal anastomoses were performed during a single clamp application. If a crossclamp could not be safely applied, the distal anastomoses were performed under fibrillation (13\% of the CPB-CABG group).

In the identified patient subset with grade 4 or 5 atheromatous disease of the ascending aorta or aortic arch, 281 patients underwent OPCAB surgery and 704 patients underwent CPB-CABG. To reduce the influence of selection on the comparison of outcome, we used propensity-score pairwise matching of patients undergoing off-pump surgery to the pool of available patients undergoing on-pump surgery as has been described. ${ }^{24,30,31}$ The propensity matched-pairs analysis is a balancing score method that attempts to correct bias in patient selection by creating equivalent risk groups for analysis. The propensity score provides the probability that patients received a particular treatment, in this case OPCAB. Patients from the off-pump and on-pump groups were matched by using this propensity score so that the treatment outcomes could be compared.

By use of multivariable logistic regression, we determined the independent factors associated with group membership (OPCAB vs CPB-CABG). These factors (Appendix 1) included ejection fraction less than $30 \%$, urgent or emergency operation, previous myocardial infarction (MI), prior stroke or cerebrovascular disease, previous cardiac operation, and number of grafts performed. After this parsimonious model was created, we established a saturated model by adding other important clinical variables. These factors included renal insufficiency, age, gender, congestive heart failure, diabetes, peripheral vascular disease, calcified ascending aorta, and chronic obstructive pulmonary disease. Finally, patients in the on-pump group were matched to patients in the off-pump group by use of a greedy matching strategy. ${ }^{32,33}$ The matched cohorts of 245 patients each are the subjects of this study. Patient data were prospectively collected by trained nurse clinicians according to the definitions used by the New York State Cardiac Surgery Reporting Form, an independently audited data collection instrument used to record and analyze all cardiac surgery performed in New York State. According to this nomencla- 
TABLE 1. Comparison of patient preoperative clinical characteristics in the study groups

\begin{tabular}{lccc}
\hline & $\begin{array}{c}\text { OPCAB } \\
\mathbf{n}=\mathbf{2 4 5}\end{array}$ & $\begin{array}{c}\text { CPB-CABG } \\
\mathbf{n}=\mathbf{2 4 5}\end{array}$ & $\boldsymbol{P}$ value \\
\hline Mean age $(\mathrm{y}) \pm \mathrm{SD}$ & $73 \pm 8$ & $73 \pm 9$ & .9 \\
Age $\geq 80 \mathrm{y}$ & $55(22.4 \%)$ & $50(20.4 \%)$ & .58 \\
Female gender & $80(32.7 \%)$ & $73(29.8 \%)$ & .50 \\
Urgent or emergency operation & $212(86.5 \%)$ & $224(91.4 \%)$ & .08 \\
Renal disease & $33(13.5 \%)$ & $29(11.8 \%)$ & .59 \\
History of stroke or & $75(30.6 \%)$ & $76(31.0 \%)$ & .92 \\
$\quad$ cerebrovascular disease & & & \\
Preoperative IABP & $8(3.3 \%)$ & $3(1.2 \%)$ & .22 \\
EF $<30 \%$ & $40(16.3 \%)$ & $43(17.6 \%)$ & .72 \\
CHF & $74(30.2 \%)$ & $75(30.6 \%)$ & .92 \\
Acute MI & $13(5.3 \%)$ & $5(2 \%)$ & .09 \\
PVD & $72(29.4 \%)$ & $79(32.2 \%)$ & .49 \\
Previous cardiac operation & $20(8.2 \%)$ & $14(5.7 \%)$ & .29 \\
Diabetes & $72(29.4 \%)$ & $75(30.6 \%)$ & .77 \\
COPD & $45(18.4 \%)$ & $45(18.4 \%)$ & 1.0 \\
\hline
\end{tabular}

$C A B G$, Coronary artery bypass graft; $C O P D$, chronic obstructive pulmonary disease; $E F$, ejection fraction; $I A B P$, intra-aortic balloon pump; $M I$, myocardial infarction; $O P C A B$, off-pump coronary artery bypass; $P V D$, peripheral vascular disease; $C P B$, cardiopulmonary bypass; $C H F$, congestive heart failure.

ture, stroke is defined as a permanent new focal neurologic deficit that occurs anytime during the postoperative hospitalization and/or new findings on computed tomography or magnetic resonance imaging. Follow-up survival was ascertained from the Social Security Death Index. ${ }^{34}$

Statistical models were formed and analyzed on a computer using SPSS and SAS statistical software (SPSS, Inc, Chicago, Ill; SAS Institute Inc, Cary, NC). The chi-square test was used to calculate the probability value for the comparison of dichotomous variables. Fisher's exact test (2-sided) was used when the number in any cell was less than 5. Survival analysis was performed using life table methodology, and differences were tested with a Wilcoxon statistic. Values are expressed as the mean \pm SD unless otherwise indicated.

\section{Results}

Table 1 lists the patients' clinical characteristics and risk factors by operative type. Preoperative characteristics of patients in the CPB-CABG and OPCAB groups were fully matched and balanced in terms of risk factor distribution, with a propensity score difference of 0.003 between groups. Most of the patients underwent urgent or emergency operations, one fifth were octogenarians, and approximately one third had a history of stroke or cerebrovascular disease. Emergency operations occurred in 40 patients (16.3\%) of the OPCAB group and in 33 patients (13.5\%) of the CPBCABG group $(P=.37)$. The intraoperative and postoperative data are summarized in Table 2 . The mean number of bypass grafts was $2.3 \pm 0.8$ in both groups. Overall hospital mortality in the OPCAB group was 6.5\% (16/245) versus $11.4 \%(28 / 245)$ in the CPB-CABG group $\left(\chi^{2}=3.6, P=\right.$
.058). Reoperation for bleeding, intensive care unit length of stay, hospital length of stay, and occurrence of any major complication were significantly reduced with the OPCAB technique. By comparison, all the patients in the CABG group during the same time period $(\mathrm{n}=5976)$ had a raw mortality of $3.7 \%$ and a stroke complication of $1.9 \%$.

Multivariable analysis revealed (Table 3) that the CPBCABG technique, fewer grafts, acute MI, chronic obstructive pulmonary disease, previous cardiac operations, and peripheral vascular disease were significantly associated with increased hospital mortality; the operative year and surgeon had no impact on mortality.

Stroke occurred in $5.7 \%$ of the patients in the CPBCABG group and in $1.6 \%$ of the patients in the OPCAB group $(P=.03)$. Multivariable analysis revealed that $\mathrm{CPB}$ was the only independent risk factor for stroke (odds ratio $=$ 3.6 , confidence interval $=1.2-11.0, P=.03$ ). Previous stroke or cerebrovascular disease were borderline significant risk factors for perioperative stroke (odds ratio $=2.5$, confidence interval $=1.0-6.5, P=.06$ ). Table 2 demonstrates that compared with the patients in the CPB-CABG group, patients in the OPCAB group underwent fewer reexplorations for bleeding, had shorter intensive care unit stays, and had a shorter total hospital length of stay. A higher percentage of patients in the OPCAB group were free from any major complication. Fewer patients in the OPCAB group received red blood cell transfusions than patients in the CPB-CABG group $(68.4 \%$ vs $86.9 \%$; $P<.001)$. In addition, less total blood bank costs were associated with patients in the OPCAB group (median $\$ 1200$ vs $\$ 3132 ; P<$ $.001)$.

A 3-year follow-up of the hospital survivors revealed no difference in mortality between the OPCAB and CPBCABG groups (Figure 1). Cox regression analysis of these patients revealed that renal disease, previous MI, advanced age, and fewer grafts were the significant risks for death (Table 4). The operative technique (OPCAB or CPBCABG) had no significant impact on late survival.

\section{Discussion \\ Survival Benefit}

The current study shows that the OPCAB technique in patients with severe atheromatous aortic disease is associated with a lower risk of death, stroke, and all complications when compared with conventional CABG. Although our initial univariate analysis demonstrated an equivocal significance $(P=.058)$, the subsequent multivariable analysis demonstrated a very strong decrease in mortality associated with the OPCAB technique $(P=.01)$. Most previous studies of selected high-risk patient groups (patients with prior neurologic events, prior cardiac surgery, impaired left ventricular function, or advanced age) undergoing CABG have failed to clearly demonstrate a significant difference in 
TABLE 2. Comparison of intraoperative and postoperative data between CPB-CABG and OPCAB groups

\begin{tabular}{|c|c|c|c|}
\hline Variable & $\begin{array}{c}\text { OPCAB } \\
(n=245)\end{array}$ & $\begin{array}{l}\text { CPB-CABG } \\
(n=245)\end{array}$ & $P$ value \\
\hline Bypass time $(\mathrm{min}) \pm S D$ & - & $97 \pm 44$ & \\
\hline Crossclamp time* $(\mathrm{min}) \pm \mathrm{SD}$ & - & $53 \pm 31$ & \\
\hline Number of grafts distal anastomoses (mean \pm SD) & $2.3 \pm 0.8$ & $2.3 \pm 0.8$ & .5 \\
\hline Hospital mortality $(\%)$ & $16(6.5 \%)$ & $28(11.4 \%)$ & .058 \\
\hline Reoperation for postoperative bleeding (\%) & $1(0.4 \%)$ & $8(3.3 \%)$ & .04 \\
\hline Deep wound infection (\%) & $1(0.4 \%)$ & $2(0.8 \%)$ & .62 \\
\hline Sepsis $(\%)$ & $2(0.8 \%)$ & $8(3.3 \%)$ & .11 \\
\hline New renal failure $(\%)$ & $6(2.4 \%)$ & $9(3.7 \%)$ & 6 \\
\hline Prolonged respiratory failure (\%) & $13(5.3 \%)$ & $23(9.4 \%)$ & .08 \\
\hline Stroke (all neurologic events) $(\%)$ & $4(1.6 \%)$ & $14(5.7 \%)$ & .03 \\
\hline Length of ICU stay (median) & 1 & 1 & .001 \\
\hline$($ mean \pm SEM) & $2.8 \pm 0.4$ & $4.6 \pm 1.0$ & \\
\hline Length of hospital stay & 7 & 9 & $<.001$ \\
\hline Complication-free $(\%)$ & $226(92.2 \%)$ & $196(80.0 \%)$ & $<.001$ \\
\hline
\end{tabular}

ICU, Intensive care unit.

*Thirty-two patients (13\%) had CPB using fibrillation without crossclamp application.

\section{TABLE 3. Multivariable analysis of hospital mortality}

\begin{tabular}{lccc}
\hline Risk factor & Exp B & 95\% Cl & P value \\
\hline Age & - & - & .17 \\
Fewer number of grafts & - & - & .05 \\
$\quad$ performed & 11.5 & $3.5-38.5$ & $<.001$ \\
Acute MI & 2.7 & $1.2-5.9$ & .01 \\
CPB-CABG & 2.4 & $1.1-5.1$ & .03 \\
COPD & 2.2 & $0.9-0.5$ & .08 \\
History of renal disease & 2.1 & $1.0-4.5$ & .05 \\
PVD & 2.0 & $0.89-4.5$ & .09 \\
CHF & 0.5 & $0.2-1.2$ & .13 \\
EF $<30 \%$ & 10.2 & $1.0-108.9$ & .05 \\
Previous cardiac surgery & 2.05 & $0.95-4.4$ & .06 \\
History of stroke or & & & \\
$\quad$ cerebrovascular & & & \\
$\quad$ disease & & & \\
\hline
\end{tabular}

Surgeon identity and operative year were not significant risk factors for mortality. $\mathrm{Cl}$, Confidence interval.

operative mortality between $\mathrm{OPCAB}$ and $\mathrm{CPB} .{ }^{35-37} \mathrm{Al}-$ though the group from Harefield, United Kingdom, ${ }^{18,22}$ reported lower mortality with the OPCAB technique in both high-risk (EuroSCORE $\geq 5$ ) and elderly patients, these studies did not involve randomization or case matching. A recent propensity case-matched study reported superior hospital outcome with OPCAB surgery in high-risk patients, but the matching did not include age or number of grafts performed, ${ }^{25}$ factors that can additionally affect outcome. ${ }^{28}$

Severe atherosclerosis of the ascending aorta and arch has been shown to increase the risk of both mortality and perioperative stroke in patients undergoing CABG. ${ }^{1,26,38}$ The hospital mortality in our CPB group of $11.4 \%$ was comparable to the $14.3 \%$ reported by Wareing and colleagues $^{4}$ for patients with ascending aortic disease not receiving the aggressive approach of graft replacement of the
TABLE 4. Multivariable analysis of postdischarge survival

\begin{tabular}{lccc}
\hline Risk factor & Exp B & 95\% Cl & $\boldsymbol{P}$ value \\
\hline Age & - & - & .001 \\
Lower number of graft & - & - & .02 \\
Renal disease & 2.7 & $1.7-4.5$ & $<.001$ \\
Previous MI & 1.7 & $1.1-2.7$ & .03 \\
CPB & 1.0 & $0.6-1.6$ & .87 \\
\hline
\end{tabular}

aorta. It should be noted, therefore, that the difference in hospital mortality between the OPCAB and CPB techniques presented here does not reflect excessive mortality in the CPB group, but rather a reduction in mortality in the OP$\mathrm{CAB}$ group. We believe that this is the first study to demonstrate a hospital survival benefit for the OPCAB technique in this specific high-risk patient subset, validating previous observations in non-case-matched studies. ${ }^{28}$ In addition, this study reinforces the fact that clinically significant atheromatous disease of the aorta is located in the transverse arch, without necessarily affecting the ascending aorta. $^{27}$

Our data also demonstrate equivalent postdischarge survival between the OPCAB and $\mathrm{CPB}$ groups. This equivalent midterm follow-up is similar to previous reports of both low-risk ${ }^{39}$ and high-risk patients. ${ }^{25}$ Renal dysfunction, previous MI, advanced age, and fewer bypass grafts were the only significant risks for late death.

\section{Neurologic Impact}

The reduction in stroke prevalence associated with use of the OPCAB technique in our study is comparable to that in previous non-case-matched studies ${ }^{19,21}$ and in 1 propensity case-matched study of a nonselective group of patients. ${ }^{23}$ The present findings, however, contrast with those of the 


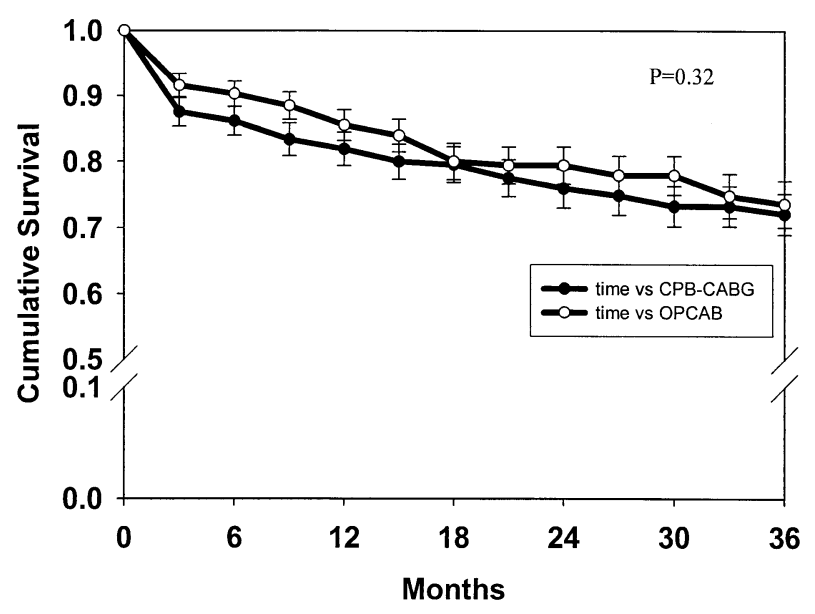

Figure 1. Life table analysis of survival by surgical technique (CPB-CABG vs OPCAB). CPB, Cardiopulmonary bypass; CABG, coronary artery bypass graft; $O P C A B$, off-pump coronary artery bypass.

propensity case-matched study of Sabik and colleagues, ${ }^{24}$ which was unable to demonstrate a reduction in stroke with OPCAB surgery. Nevertheless, close examination of Sabik's data reveals equivalent neurologic outcomes in the OPCAB and CABG groups despite the OPCAB group's significantly greater prevalence of pulmonary vascular disease and history of stroke. A positive neurologic impact in their study may have been underestimated by such risk factors that were not included in their propensity matching but are generally associated with higher neurologic complication prevalence.

We identified patients with severely atheromatous ascending aortas or arches for this study on the basis of our previous work indicating that the risk of perioperative neurologic complications in $\mathrm{CABG}$ and other operative procedures is directly related to the severity of the aortic atheroma as graded by TEE. ${ }^{10,40}$ It is known that the stroke prevalence is still high for patients with moderate or severe ascending aortic disease when minor modifications in surgical strategy with CPB (guided by epiaortic scanning) are used, ${ }^{4}$ and that the mortality is excessive $(24.8 \%)$ for patients who do have a stroke. ${ }^{41}$ Therefore, although the previously mentioned avoidance or limited manipulation of the ascending aorta in patients with severe atheromatous aortic disease is important, ${ }^{42}$ there stills remains significant risk. We speculate that atheromatous disease in aortic arch disease is a contributor to atheroemboli from CPB-induced flow-pattern changes. ${ }^{7}$ Although limited atherectomy or graft replacement has its advocates, ${ }^{12}$ we would argue that in these patients "the only way to win is not to play." In this high-risk patient subset, avoidance of CPB serves the patients better, as our results demonstrate.

\section{Limitations}

Although patient data were collected prospectively, a limitation of this study is that the decision to perform OPCAB surgery was not randomized. However, by using the propensity score-matching analysis, we attempted to minimize bias between the OPCAB and the CPB-CABG groups. ${ }^{43,44}$ Indeed, the $\mathrm{CPB}$ and $\mathrm{OPCAB}$ groups had an approximately equal distribution of all significant preoperative variables. However, a limitation of this analytic technique is that it accounts for only identified variables. Although we made every attempt to acknowledge all clinically significant variables, it is possible that an effect may exist from an unquantified variable. This series also encompasses our "learning curve" for OPCAB surgery, including our initial experiences.

\section{Conclusions}

Intraoperative TEE is indicated in all patients undergoing operative coronary revascularization because it allows timely identification of patients at high risk for a neurologic event associated with CPB. Use of the OPCAB technique in these high-risk patients minimizes hospital mortality, neurologic complications, and overall morbidity.

\section{References}

1. Roach GW, Kanchuger M, Mangano CM, et al. Adverse cerebral outcomes after coronary bypass surgery. Multicenter Study of Perioperative Ischemia Research Group and the Ischemia Research and Education Foundation Investigators. N Engl J Med. 1996;335:1857-63.

2. Hosoda Y, Watanabe M, Hirooka Y, et al. Significance of atherosclerotic changes of the ascending aorta during coronary bypass surgery with intraoperative detection by echography. J Cardiovasc Surg (Torino). 1991;32:301-6.

3. Davila-Roman VG, Murphy SF, Nickerson NJ, et al. Atherosclerosis of the ascending aorta is an independent predictor of long-term neurologic events and mortality. J Am Coll Cardiol. 1999;33:1308-16.

4. Wareing TH, Davila-Roman VG, Daily BB, et al. Strategy for the reduction of stroke incidence in cardiac surgical patients. Ann Thorac Surg. 1993;55:1400-8.

5. Mills NL, Everson CT. Atherosclerosis of the ascending aorta and coronary artery bypass. Pathology, clinical correlates, and operative management. J Thorac Cardiovasc Surg. 1991;102:546-53.

6. Cosgrove DM. Management of the calcified aorta: an alternative method of occlusion. Ann Thorac Surg. 1983;36:718-9.

7. Grossi EA, Kanchuger MS, Schwartz DS, et al. Effect of cannula length on aortic arch flow: protection of the atheromatous aortic arch [see comments]. Ann Thorac Surg. 1995;59:710-2.

8. Bar-El Y, Goor DA. Clamping of the atherosclerotic ascending aorta during coronary artery bypass operations. Its cost in strokes. $J$ Thorac Cardiovasc Surg. 1992;104:469-74.

9. Peigh PS, DiSesa VJ, Collins JJ Jr, et al. Coronary bypass grafting with totally calcified or acutely dissected ascending aorta. Ann Thorac Surg. 1991;51:102-4.

10. Stern A, Tunick PA, Culliford AT, et al. Protruding aortic arch atheromas: risk of stroke during heart surgery with and without aortic arch endarterectomy. Am Heart J. 1999;138:746-52.

11. Swanson SJ, Cohn LH. Excision of focal aortic arch atheroma using deep hypothermic circulatory arrest. Ann Thorac Surg. 1995;60:457-8.

12. Rokkas CK, Kouchoukos NT. Surgical management of the severely atherosclerotic ascending aorta during cardiac operations. Semin Thorac Cardiovasc Surg. 1998;10:240-6.

13. Wimmer-Greinecker G. Reduction of neurologic complications by 
intra-aortic filtration in patients undergoing combined intracardiac and CABG procedures. Eur J Cardiothorac Surg. 2003;23:159-64.

14. Arom KV, Flavin TF, Emery RW, et al. Safety and efficacy of off-pump coronary artery bypass grafting. Ann Thorac Surg. 2000;69: 704-10.

15. Hernandez F, Cohn WE, Baribeau YR, et al. In-hospital outcomes of off-pump versus on-pump coronary artery bypass procedures: a multicenter experience. Ann Thorac Surg. 2001;72:1528-34.

16. Hart JC, Puskas JD, Sabik JF 3rd. Off-pump coronary revascularization: current state of the art. Semin Thorac Cardiovasc Surg. 2002;14: 70-81.

17. Meharwal ZS, Mishra YK, Kohli V, et al. Off-pump multivessel coronary artery surgery in high-risk patients. Ann Thorac Surg. 2002; 74:S1353-7.

18. Al-Ruzzeh S, George S, Yacoub M, et al. The clinical outcome of off-pump coronary artery bypass surgery in the elderly patients. Eur J Cardiothorac Surg. 2001;20:1152-6.

19. Patel NC, Pullan DM, Fabri BM. Does off-pump total arterial revascularization without aortic manipulation influence neurological outcome? A study of 226 consecutive, unselected cases. Heart Surg Forum. 2002;5:28-32.

20. Novick RJ, Fox SA, Stitt LW, et al. Effect of off-pump coronary artery bypass grafting on risk-adjusted and cumulative sum failure outcomes after coronary artery surgery. J Card Surg. 2002;17:520-8.

21. Lev-Ran O, Ben-Gal Y, Matsa M, et al. "No touch" techniques for porcelain ascending aorta: comparison between cardiopulmonary bypass with femoral artery cannulation and off-pump myocardial revascularization. J Card Surg. 2002;17:370-6.

22. Al-Ruzzeh S, Nakamura $\mathrm{K}$, Athanasiou $\mathrm{T}$, et al. Does off-pump coronary artery bypass (OPCAB) surgery improve the outcome in high-risk patients? a comparative study of 1398 high-risk patients. Eur J Cardiothorac Surg. 2003;23:50-5.

23. Stamou SC, Jablonski KA, Pfister AJ, et al. Stroke after conventional versus minimally invasive coronary artery bypass. Ann Thorac Surg. 2002;74:394-9.

24. Sabik JF, Gillinov AM, Blackstone EH, et al. Does off-pump coronary surgery reduce morbidity and mortality? J Thorac Cardiovasc Surg. 2002;124:698-707.

25. Calafiore AM, Di Mauro M, Canosa C, et al. Early and late outcome of myocardial revascularization with and without cardiopulmonary bypass in high risk patients (EuroSCORE $>/=6$ ). Eur J Cardiothorac Surg. 2003;23:360-7.

26. Katz ES, Tunick PA, Rusinek H, et al. Protruding aortic atheromas predict stroke in elderly patients undergoing cardiopulmonary bypass: experience with intraoperative transesophageal echocardiography. J Am Coll Cardiol. 1992;20:70-7.

27. Marschall K, Kanchuger M, Kessler K, et al. Superiority of transesophageal echocardiography in detecting aortic arch atheromatous disease: identification of patients at increased risk of stroke during cardiac surgery. J Cardiothorac Vasc Anesth. 1994;8:5-13.

28. Grossi EA, Bizekis CS, Sharony R, et al. Routine intraoperative TEE identifies patients with atheromatous aortas: impact on "off pump" coronary artery bypass and perioperative stroke. J Am Soc Echocardiogr. 2003;16:751-5.

29. Ostrowski JW, Kanchuger MS. Con: epiaortic scanning is not routinely necessary for cardiac surgery. J Cardiothorac Vasc Anesth. 2000;14:91-4.

30. Rosenbaum PR, Rubin DB. The central role of the propensity score in observational studies for causal effects. Biometrika. 1983;70:41-55.

31. Joffe MM, Rosenbaum PR. Invited commentary: propensity scores. Am J Epidemiol. 1999;150:327-33.

32. Parsons LS. Reducing bias in propensity score matched-pair sample using greedy matching techniques. Proceedings of the Twenty-Sixth Annual SAS Users Group International Conference. Cary, NC: SAS Institute Inc; April 22-25, 2001. p. 214-6.

33. D'Agostino RB Jr. Propensity score methods for bias reduction in the comparison of a treatment to a non-randomized control group. Stat Med. 1998;17:2265-81.

34. Hill ME, Rosenwaike I. The Social Security Administration's Death Master File: the completeness of death reporting at older ages. Soc Secur Bull. 2001;64:45-51.
35. Yokoyama T, Baumgartner FJ, Gheissari A, et al. Off-pump versus on-pump coronary bypass in high-risk subgroups. Ann Thorac Surg. 2000;70:1546-50.

36. D'Ancona G, Karamanoukian H, Kawaguchi AT, et al. Myocardial revascularization of the beating heart in high-risk patients. $J$ Card Surg. 2001;16:132-9.

37. Demers P, Cartier R. Multivessel off-pump coronary artery bypass surgery in the elderly. Eur J Cardiothorac Surg. 2001;20:908-12.

38. Gardner TJ, Horneffer PJ, Manolio TA, et al. Stroke following coronary artery bypass grafting: a ten-year study. Ann Thorac Surg. 1985; 40:574-81.

39. Nathoe HM, van Dijk D, Jansen EW, et al. A comparison of on-pump and off-pump coronary bypass surgery in low-risk patients. $N$ Engl J Med. 2003;348:394-402.

40. Ribakove GH, Katz ES, Galloway AC, et al. Surgical implications of transesophageal echocardiography to grade the atheromatous aortic arch. Ann Thorac Surg. 1992;53:758-63.

41. John R, Choudhri AF, Weinberg AD, et al. Multicenter review of preoperative risk factors for stroke after coronary artery bypass grafting. Ann Thorac Surg. 2000;69:30-6.

42. Calafiore AM, Di Mauro M, Teodori G, et al. Impact of aortic manipulation on incidence of cerebrovascular accidents after surgical myocardial revascularization. Ann Thorac Surg. 2002;73:1387-93.

43. Blackstone EH. Comparing apples and oranges. J Thorac Cardiovasc Surg. 2002;123:8-15.

44. Grunkemeier GL, Payne N, Jin R, et al. Propensity score analysis of stroke after off-pump coronary artery bypass grafting. Ann Thorac Surg. 2002;74:301-5.

\section{APPENDIX 1}

Multivariable analysis of preoperative risk factors associated with OPCAB in 985 patients

\begin{tabular}{lccc}
\hline Risk factor & OR & 95\% CI & $\boldsymbol{P}$ value \\
\hline EF $<30 \%$ & 2.3 & $1.5-3.7$ & $<.01$ \\
Urgent/emergency operation & 2.5 & $1.6-3.8$ & $<.01$ \\
Previous MI & 0.6 & $0.4-0.8$ & $<.01$ \\
Increased number of grafts performed & 0.3 & $0.3-0.4$ & $<.01$ \\
Previous cardiac surgery & 0.4 & $0.2-0.8$ & $<.01$ \\
History of stroke or cerebrovascular & 1.5 & $1.1-2.3$ & .01 \\
$\quad$ disease & & & \\
\hline
\end{tabular}

The following factors were not significantly associated with group membership but were added to create the saturated model: renal insufficiency, age, gender, congestive heart failure, diabetes, peripheral vascular disease, calcified ascending aorta, and chronic obstructive pulmonary disease.

$E F$, Ejection fraction; $M I$, myocardial infarction; $O P C A B$, off-pump coronary artery bypass; $O R$, odds ratio; $C l$, confidence interval.

\section{Discussion}

Dr Nicholas T. Kouchoukos (St Louis, Mo). In this study comparing off-pump and on-pump surgery for patients with coronary artery disease, Dr Sharony and his colleagues examined a subset of patients who are known to be at increased risk for a postoperative neurologic event: those with severe atherosclerosis of the ascending aorta or the aortic arch that has been identified by intraoperative TEE. Using propensity matched-pairs analysis, they demonstrated a lower hospital mortality, a lower prevalence of stroke, and a greater freedom from any postoperative complication among the patients in the off-pump group. They thus provided new and important information indicating that OPCAB grafting may be of particular benefit in this high-risk subset of patients with coronary artery disease. I want to focus my subsequent comments on the complication of stroke. Although propensity matched-pairs 
analysis was used in patients with comparable preoperative characteristics, which certainly strengthens the validity of the analyses and the conclusions, this was, nevertheless, a retrospective study and is therefore subject to the usual criticisms that are leveled at such studies.

Intraoperative TEE was used to identify the presence of severe atherosclerosis in this study, and the New York University group pioneered the use of TEE in patients undergoing cardiac surgery. However, several studies, including one from our institution, have demonstrated that TEE underestimates the prevalence and severity of aortic atherosclerosis in the ascending aorta when compared with epiaortic scanning. Although the article indicates that epiaortic scanning was routinely performed when aortic disease was identified by TEE, and this was presumably done for corroboration, no information was provided as to how this information from scanning was used. Is it possible that patients with severe aortic disease were excluded from the study group because the severity was underestimated because only TEE was used to identify its presence?

There was no mention of specific interventions to prevent or minimize the risk of atheroembolization once severe atherosclerosis was detected for either of the 2 therapeutic groups. It is common in many practices, including our own, to make modifications in technique, such as the use of alternative sites for cannulation and clamping, use of only pedicled arterial grafts, resection and replacement of the severely atherosclerotic aorta, and others, when severe atherosclerosis is detected. Were any such interventions used in either group?

The authors demonstrated in their multivariate analysis that use of CPB was the only independent risk factor for stroke. Is it possible that other variables related to surgical technique that were not included in the analyses could have contributed to the differences in stroke?

As Dr Blackstone and others have pointed out, propensity score methodology is seriously degraded when other important variables influencing selection are not collected.

Although atherosclerotic disease is a major risk factor for stroke, other important risk factors for postoperative stroke also exist. Highly obstructive carotid artery disease documented by preoperative duplex scanning or angiography and postoperative atrial fibrillation are 2 of these. From the presentation and from my review of the article, these 2 variables were not entered into the model. Could differences in the prevalence of these 2 variables account for some or all of the differences in the stroke rates?

Although the controversy regarding the beneficial effect of OPCAB grafting on the prevalence of postoperative stroke has not been resolved, Dr Sharony and his colleagues have provided highly suggestive evidence that it may be beneficial in patients who are known to be at increased risk for stroke because of the presence of severe aortic atherosclerosis, and they are to be commended. But perhaps it is time for a large, multicenter, randomized trial to establish conclusively whether OPCAB will substantially reduce the presence of this important complication. Because the mortality and stroke rates are increased for patients with aortic atherosclerosis compared with the general population, and this was shown in their study and in our studies as well using epiaortic scanning, it should be possible to demonstrate substantial differ- ences, if they exist, without extraordinarily large numbers of patients.

Dr John W. Hammon, Jr (Winston-Salem, NC). I also congratulate the New York University group for their careful analysis of their data. I think that is something that we all need to do more often.

I would like to ask 1 question, and it is a variation on a theme of Dr Kouchoukos' third question regarding variables that might be overlooked or missed by your propensity-matched analysis. Your group was analyzed during the entire decade of the 1990s, and most OPCAB surgery was performed in the latter part of the 1990s. Are you comparing OPCAB operations that were performed in the late 1990s with coronary bypass operations performed on-pump in the early 1990s when some of the tools to identify aortic atherosclerosis, to avoid it, and other techniques to avoid intraoperative embolization, were present?

Dr Lawrence I. Bonchek (Lancaster, $\mathrm{Pa}$ ). It would be difficult to add anything to Dr Kouchoukos' thorough analysis, but when OPCAB is compared with operations performed with $\mathrm{CPB}$, neither of those procedures should be treated as a commodity. Everyone performs operations differently, and I would also make a plea for you to tell us more about your technique. For example, did you ever perform operations with $\mathrm{CPB}$ without any clamping of the aorta, by doing proximal anastomoses to the aorta with a brief period of circulatory arrest and distal anastomoses without cardioplegia but with ventricular fibrillation and local control of the grafted artery? That is the approach we take with bad aortas, and with those maneuvers we find the stroke rates on pump to be quite acceptable.

Dr Vivek Rao (Toronto, Ontario, Canada). I echo what the previous discussants have said. It was not clear in your presentation if, in your on-pump group, other procedures were done in addition to bypass surgery-most notably that of replacement of the ascending aorta. Clearly, that procedure is going to increase your perioperative stroke rate; however, it might reduce the longterm risk of ascending aortic atheroma.

Perhaps the lack of difference you saw in your survival curves was because atheroma was addressed at the initial operation in the on-pump group, and that group was at lower risk for future stroke events. Whereas in the OPCAB group, you really did not do anything about the patients' aortic atheroma, and that might be one of the causes of late events in these patients.

Dr O. Wayne Isom (New York, NY). I enjoyed the article very much. One other question. We found a number of years ago at New York Hospital that with atherosclerotic aortas there was a big difference in the incidence of stroke rate with the varying of pressures. What kind of pressures did you run during CPB?

Dr Sharony. Thank you to all the discussants for their comments, and I will try to answer question by question.

First, we consider intraoperative TEE the primary tool to identify severe atheromatous disease of the arch and the ascending aorta. Everybody knows that TEE has some limitations in the distal part of the ascending aorta because of the interposition of the trachea and the main stem bronchus. However, it has been shown in our institution by Tissot and Kanchuger that TEE combined with palpation, which by itself has a low sensitivity, results in 0 false negatives. This means if we perform TEE and palpation and 
both are negative, we are confident that there is no severe atheromatous disease of the ascending aorta. Yes, although there is low probability that TEE alone may miss some disease, our combined evaluation, especially with the capability of the newer multiplane TEE probes, decreases the chance that we will miss significant lesions in the ascending aorta. Regarding specific interventions used in either group to minimize the risk of atheroembolism, in the absence of ascending aortic disease, we perform the proximal anastomoses before CPB and the distal anastomoses during a single crossclamp. However, when there is concern of atheromatous disease in the ascending aorta and CPB is used, epiaortic scanning is performed for disease localization, and the proximals and distals are created during the single aortic crossclamp. Currently, if we identify severe ascending atheromatous aortic disease, we apply a no-touch technique to the aorta with the OPCAB technique. This can be accomplished with in situ arterial grafts serving as inflow for secondary bypass grafts. Again, I stress that the majority of patients in this report had severe atheromatous disease limited to the transverse arch. The implication from this study is that when CPB is used, embolic material originates from the arch and maneuvers to avoid ascending aortic disease will not have any impact in these patients.

Regarding other variables relating to the surgical techniques that were not included in the analysis (disregarding that the only predictor by multivariate analysis was $\mathrm{CPB}-\mathrm{CABG}$ as a predictor for stroke), we entered all the parameters in our multivariate analysis, and the only one found to be significant was CPB-CABG. Regarding obstructive carotid disease and atrial fibrillation, we did match patients on the presence of obstructive carotid disease; however, we did not match for preoperative atrial fibrillation. Cerebrovascular disease includes previous stroke or significant cerebrovascular disease.

With regard to arterial perfusion pressure, we routinely maintain a perfusion pressure of approximately $70 \mathrm{~mm} \mathrm{Hg}$ during bypass, and we consider this extremely important in chronically hypertensive patients.

\section{Availability of Journal back issues}

As a service to our subscribers, copies of back issues of The Journal of Thoracic and Cardiovascular Surgery for the preceding 5 years are maintained and are available for purchase from Elsevier Inc. until inventory is depleted. Please write to Elsevier Inc., Subscription Customer Service, 6277 Sea Harbor Dr, Orlando, FL 32877 , or call $800-654-2452$ or $407-345-4000$ for information on availability of particular issues and prices. 